\title{
Contribuições e dificuldades do uso das simulações para o processo ensino e aprendizagem de Genética
}

\author{
Contributions and difficulties of using simulations for the teaching and learning process of Genetics
}

Contribuciones y dificultades en el uso de simulaciones para el proceso de enseñanza y aprendizaje

de la Genética

Recebido: 19/09/2021 | Revisado: 24/09/2021 | Aceito: 26/09/2021 | Publicado: 27/09/2021

\author{
Marisa Inês Bilthauer \\ ORCID: https://orcid.org/0000-0003-0566-0748 \\ Universidade Estadual de Maringá, Brasil \\ E-mail bilthauer@gmail.com \\ Dulcinéia Ester Pagani Gianotto \\ ORCID: https://orcid.org/0000-0003-0156-4521 \\ Universidade Estadual de Maringá, Brasil \\ E-mail: depgianoto@uem.br
}

\begin{abstract}
Resumo
As tecnologias da informação e comunicação - TIC estão inseridas no cotidiano da população interferindo nas relações sociais, profissionais e educacionais. Dentre os recursos interativos propiciados pelas TIC, estão os objetos de aprendizagem, entre os quais as simulações. Assim, o presente artigo apresenta resultados parciais de uma pesquisa de doutorado $^{1}$, e tem como objetivo investigar quais as contribuições, potencialidades e dificuldades do uso de simulações para o processo ensino e aprendizagem de Genética, de acordo com os alunos do $4^{\circ}$ ano do Curso de Administração Integrado em uma escola da rede pública do município de Paranavaí. A metodologia adotada é de natureza qualitativa, do tipo observação participante, na qual foi implementada uma sequência didática, utilizando os recursos do Google Sala de Aula, associado ao uso de simulações. Posteriormente foi aplicado um questionário pósteste cujos resultados apresentam-se neste artigo. Entre as principais vantagens do ambiente elencadas pelos alunos estão: facilitam a aprendizagem dos conceitos de Genética e possibilitam a diversificação metodológica. E como aspectos positivos: facilitar a aprendizagem, a organização e praticidade dos recursos; tornar a aula mais dinâmica; a ilustração e a facilidade de acesso. E como aspectos negativos: dificuldade e complexidade na execução das atividades; o acesso à internet; e a baixa qualidade na aparência das simulações. Concluiu-se que o uso de simulações, pode ser uma excelente ferramenta para fins didático-pedagógico, se for utilizado de maneira planejada, pois pode vir a facilitar a aprendizagem, possibilitar uma diversificação metodológica; auxiliar na organização de conteúdos e na interação entre os participantes.
\end{abstract}

Palavras-chave: TIC; Objetos de aprendizagem; Simulações; Ensino de biologia.

\begin{abstract}
Information and communication technologies - ICT are inserted in the daily life of the population, interfering in social, professional and educational relationships. Among the interactive resources provided by ICT are learning objects, including simulations. Thus, this article presents partial results of a doctoral research, and aims to investigate the contributions, potentials and difficulties of using simulations for the teaching and learning process of Genetics, according to the 4th year students of the Integrated Administration in a public school in the city of Paranavaí. The methodology adopted is of a qualitative nature, of the participant observation type, in which a didactic sequence was implemented, using the resources of Google Classroom, associated with the use of simulations. Subsequently, a posttest questionnaire was applied, the results of which are presented in this article. Among the main advantages of the environment listed by the students are: they facilitate the learning of genetic concepts and allow for methodological diversification. And as positive aspects: facilitate learning, organization and practicality of resources; make the class more dynamic; the illustration and the ease of access. And as negative aspects: difficulty and complexity in carrying out activities; internet access; and the low quality of appearance of the simulations. It was concluded that the use of simulations can be an excellent tool for didactic-pedagogical purposes, if used in a planned way, as it can facilitate learning, enable a methodological diversification; assist in the organization of content and in the interaction between participants.
\end{abstract}

Keywords: ICT; Learning objects; Simulations; Biology teaching.

\footnotetext{
${ }^{1}$ Pesquisa de Doutorado intitulada "Google Sala de Aula, as simulações e suas contribuições para a aprendizagem significativa dos conceitos de genética na Educação Básica"; do Programa de Pós-graduação em Educação para a Ciência e a Matemática, da Universidade Estadual de Maringá (UEM).
} 


\begin{abstract}
Resumen
Tecnologías de la información y la comunicación - Las TIC se insertan en la vida cotidiana de la población, interfiriendo en las relaciones sociales, profesionales y educativas. Entre los recursos interactivos que proporcionan las TIC se encuentran los objetos de aprendizaje, incluidas las simulaciones. Así, este artículo presenta resultados parciales de una investigación de doctorado, y tiene como objetivo indagar los aportes, potencialidades y dificultades del uso de simulaciones para el proceso de enseñanza y aprendizaje de la Genética, según los alumnos de 4o curso de la Administración Integrada en una escuela pública de la ciudad de Paranavaí. La metodología adoptada es de carácter cualitativo, de tipo observación participante, en la que se implementó una secuencia didáctica, utilizando los recursos de Google Classroom, asociada al uso de simulaciones. Posteriormente se aplicó un cuestionario post-test, cuyos resultados se presentan en este artículo. Entre las principales ventajas del entorno enumeradas por los estudiantes se encuentran: facilitan el aprendizaje de conceptos genéticos y permiten la diversificación metodológica. Y como aspectos positivos: facilitar el aprendizaje, la organización y la practicidad de los recursos; hacer la clase más dinámica; la ilustración y la facilidad de acceso. Y como aspectos negativos: dificultad y complejidad en la realización de actividades; acceso a Internet; y la baja calidad de apariencia de las simulaciones. Se concluyó que el uso de simulaciones puede ser una excelente herramienta con fines didáctico-pedagógicos, si se utiliza de forma planificada, ya que puede facilitar el aprendizaje, posibilitar una diversificación metodológica; ayudar en la organización del contenido y la interacción entre los participantes.
\end{abstract}

Palabras clave: TIC; Objetos de aprendizaje; Simulaciones; Enseñanza de biología.

\title{
1. Introdução
}

As Tecnologias da Informação e Comunicação (TICs) estão presentes atualmente nos diferentes espaços e contextos da sociedade, incluindo a escola, proporcionando assim, mudanças significativas no cotidiano das pessoas, facilitando o acesso à informação, influenciando as relações interpessoais, o mercado de trabalho e a educação. Dessa maneira, vivenciamos "uma nova forma de organização econômica, social, política e cultural, identificada como Sociedade da Informação (SI), que comporta novas maneiras de trabalhar, de comunicar-se, de relacionar-se, de aprender, de pensar e, em suma, de viver (Coll; Monereo, 2010, p. 15).

Neste contexto, o alcance aos meios de comunicação e recursos tecnológicos se tornou mais acessível, tendo em vista que boa parte dos alunos ingressam na escola já possuindo celular e/ou microcomputador com acesso à internet. Assim, "fora do ambiente escolar, contemporaneamente muitos alunos têm acesso a diversos recursos que permitem o entretenimento, a obtenção de informações, ao conhecimento de lugares distantes, à interação e à comunicação a nível mundial, em ambientes virtuais" [...] (Gianotto, 2016, p. 17). Existindo, por exemplo, a possibilidade de passeios virtuais à museus, biblioteca, parques e instituições de várias partes do mundo que estejam disponíveis de forma online.

Sendo assim, compete ao docente utilizar a seu favor esse processo de interação do educando com as mídias, valendose da grande quantidade de vídeos, imagens, animações, simulações, jogos na internet e ambientes virtuais que podem ser utilizados como recursos didáticos nas aulas nas diversas áreas de conhecimento. Pois, o "uso do computador, na educação, tem sido utilizado tanto para ensinar sobre recursos computacionais quanto para ensinar praticamente qualquer assunto utilizando programas, simulações e animações" (Gianotto, 2016, p. 7).

$\mathrm{Na}$ disciplina de Biologia, ao trabalhar com alunos os conteúdos relativos à Genética, percebe-se uma certa dificuldade destes na compreensão dos conceitos, tanto pelo nível de abstração, como pela dificuldade com a interpretação dos enunciados e a falta de conhecimentos considerados pré-requisitos, como bioquímica e probabilidade. Isso se deve, pelo fato que "o seu ensino é complexo, pois é baseado em vocabulário próprio, com conceitos abstratos, que podem dificultar o aprendizado" (Rocha, 2016, p. 4). Consequentemente, o uso de recursos tecnológicos é oportuno, tendo em vista que, pode auxiliar na visualização dos mecanismos de transmissão das características hereditárias, tornando o processo ensino e aprendizagem dessa área menos complexo e abstrato.

Dessa forma, surgiu em nossa pesquisa de doutorado, o desafio de se pesquisar a influência que as mídias exercem sobre os educandos como recurso didático no processo ensino e aprendizagem, aliando o uso de um ambiente virtual de aprendizagem, com a inserção de objetos de aprendizagem, tais como as simulações, em conjunto com a atividade de escrita e 
a interação entre os alunos. Por conseguinte, implementar uma estratégia metodológica que permitisse a participação de todos, minimizando dificuldades, mas acima de tudo, a busca de uma aprendizagem significativa.

Portanto, perante o uso das novas tecnologias de informação e comunicação, cada vez mais presentes em sala de aula, e da dificuldade dos alunos em compreender conceitos básicos da Genética Mendeliana, o presente trabalho baseia-se no seguinte problema de pesquisa: Quais as contribuições, potencialidades e dificuldades do uso de simulações para o processo ensino e aprendizagem de Genética, de acordo com os alunos do $4^{\circ}$ ano do Curso de Administração Integrado em uma escola da rede pública do município de Paranavaí.

Dessa maneira, este artigo tem como objetivo tem como objetivo investigar quais as contribuições, potencialidades e dificuldades do uso de simulações para o processo ensino e aprendizagem de Genética, de acordo com os alunos do $4^{\circ}$ ano do Curso de Administração Integrado em uma escola da rede pública do município de Paranavaí.

\subsection{Tecnologias de informação e comunicação - TIC}

A tecnologia em si é compreendida como "o conjunto de conhecimentos e princípios científicos que se aplicam ao planejamento, à construção e à utilização de um equipamento em um determinado tipo de atividade" (Kenski, 2012, p. 15-16). Assim, desde um simples lápis até um sofisticado celular, ambos são considerados produtos da tecnologia.

Miranda (2007, p. 42) por sua vez, elucida que o termo TIC não se limita apenas "aos recursos técnicos usados no ensino, mas sim, a todos os processos e concepção, desenvolvimento e avaliação da aprendizagem". Dessa forma, acrescenta a autora, as TIC referem-se ao conjunto integrado da tecnologia computacional com a tecnologia das telecomunicações, tendo na Internet, ou seja, na rede mundial de computadores, a sua a maior relevância. Por isso, quando as tecnologias são utilizadas para propósitos educacionais, especificamente para "apoiar e melhorar a aprendizagem dos alunos e desenvolver ambientes de aprendizagem, podemos considerar as TIC como um subdomínio da Tecnologia Educativa" (Miranda, 2007, p. 43).

Nesse sentido, valida Coll e Monereo (2010, p. 17) ao afirmar que dentre todas as tecnologias criadas pela humanidade, as TIC são consideradas as mais importantes, pois influenciam em "praticamente todos os âmbitos de atividade dos indivíduos, desde as formas e práticas de organização social até o modo de compreender o mundo, de organizar essa compreensão e de transmiti-la para outras pessoas" (Coll; Monereo, 2010, p.17). Essa junção da informação e da comunicação possibilita a constituição de novos ambientes de aprendizagens e de interação, acrescenta Hamze (2011).

À vista disso, "na sociedade contemporânea, existe a necessidade de se refletir sobre metodologias que proporcionem ações pedagógicas que promovam a participação ativa dos alunos no processo de aprendizagem, e assim, possibilitem a interação com os colegas e com o objeto de estudo" (Lima et al., 2021, p. 2).

Portanto, a utilização de objetos de aprendizagem pode ser primordial para a construção do conhecimento, visto que, integram processos colaborativos de ensino e aprendizagem, em razão de serem elaborados a partir de uma problemática, estimulando o raciocínio dos alunos, e auxiliando assim, na formação de cidadãos críticos.

\subsection{Objetos de aprendizagem}

Os Objetos de Aprendizagem - OA são recursos educacionais, que podem ser elaborados em "diversos formatos e linguagens, com o objetivo de mediar e qualificar o processo de ensino-aprendizagem, como por exemplo, uma animação, uma simulação, um texto, uma imagem, uma página html, vídeos, etc" (Brasil, 2020, p. 1). Assim, com o advento da Internet, é possível encontrar OA virtuais nos mais diferentes formatos, como textos, hipertextos, imagens, vídeos, sons, animações gráficas, simulações, etc. Pois, os OA "utilizam-se de imagens, animações e applets (mini aplicativo que roda dentro de uma página Web), documentos VRML (Virtual Reality Modeling Language - realidade virtual), arquivos de texto ou hipertexto, dentre outros" (Macedo et al., 2007, p. 20). Assim, podem ser compreendidos como qualquer material eletrônico que possa 
auxiliar com informações a construção do conhecimento, podendo ser uma imagem, página da web, vídeo, animação ou simulação.

Por isso, esses recursos recebem diversas denominações na literatura, tais como: "objetos educacionais, objetos de conhecimento, componentes de software educacional, conteúdos de objetos compartilháveis, objetos de aprendizagem multimídia, entre outros" (Brasil, 2020). Podendo também receber o nome de Recurso Didático Digital (RDD), definido como "todos os objetos de aprendizagem produzidos com o uso das tecnologias digitais, que auxiliam no processo de aprendizado do indivíduo" (Leite, 2015, p. 239).

Os OA são relevantes no processo ensino e aprendizagem, pois conforme Audino e Nascimento (2010), pois apresentam baixo custo de produção, nos possibilitam simular e animar fenômenos, sendo reutilizáveis em diferentes AVA, dessa forma, ficando alocados em repositórios virtuais disponíveis na internet. A reusabilidade, acrescentam os autores, é considerada a sua principal característica, permitindo o uso em diferentes AVA, por meio de repositórios nos quais os OA ficam alojados e catalogados, possibilitando a busca por temas, por nível de dificuldade, por autor ou por relação com outros objetos similares. Desse modo, por "ser reutilizável e estimular a criatividade e imaginação do aprendiz, eles enriquecem a prática do professor em sala de aula e facilitam a compreensão dos alunos" (Andrade; Scareli, 2011, p. 5).

Assim sendo, eles possibilitam reorganizar as práticas pedagógicas, propiciando novas reflexões sobre o uso dos recursos da comunicação, da informação e da interação. Assim, associados com outras mídias digitais podem garantir "situações de aprendizagem em que o educador assuma o caráter de mediador e o aluno o caráter de sujeito ativo dentro do processo de ensino e aprendizagem" (Audino; Nascimento, 2010, p. 131).

Todavia, um objeto de aprendizagem, precisa ser atraente, tendo um designer que colabore para a "elaboração de um ambiente virtual envolvente que instigue o aluno a investigar, fazer questionamentos, relacionar fatos e aplicar conhecimentos" (Nascimento, 2007, p. 139). A autora acrescenta ainda que deve conter instruções claras e objetivas de cada etapa da atividade a ser desenvolvida.

A flexibilidade de uso e reuso possibilitada pelos OA, assinala Brasil (2020), pode incrementar práticas pedagógicas que atinjam significativas melhorias no processo de construção do conhecimento. Mas para isso, o docente necessita ter seu objetivo bem definido, pois justamente o que irá definir a qualidade do recurso, está na forma como será utilizado. Assim, recomenda Brasil (2020), para o seu uso é fundamental um planejamento, evidenciando o objetivo e a metodologia a ser adotados na utilização do recurso. Para isso, o primeiro passo é conhecer o objeto que se quer utilizar, em seguida, planejar a estrutura da prática pedagógica que se pretende adotar. Simultaneamente, é necessário selecionar os conteúdos e os recursos que serão empregados na prática. Estes devem aliar o planejamento pedagógico com o recurso tecnológico, baseando-se no conteúdo estudado pela série. Deste modo, "por meio de emprego e planejamento docente adequados, as tecnologias podem ser envolvidas em uma abordagem significativa dos conteúdos" (Mesquita et al., 2021, p.4).

Esse aspecto é reforçado por Prandini (2009, p.81), para qual ao assumir a tecnologia para nos auxiliar a fazer o que desejamos, incide em melhorar o processo ensino e aprendizagem de acordo com os nossos objetivos e nossa concepção de educação. Assim, "para que um recurso tecnológico tenha um fim pedagógico, os professores devem conhecê-lo, saber utilizálo pedagogicamente e empregá-lo com uma finalidade definida voltada à formação integral do indivíduo" (Moreira, 2018, p. 19). Posto que, não se trata apenas de utilizar "novos recursos didáticos para atingir avanços e melhorias na aprendizagem dos alunos e no processo educacional" (Leite et al., 2011).

Nesse contexto, a utilização de OA, principalmente das simulações e animações, se torna eficiente, na medida em que associa o emprego de recursos tecnológicos ao trabalho pedagógico ao explorar os conceitos específicos da área de conhecimento, como as Ciências e a Biologia. 


\subsection{Simulações e animações}

Dentre os diversos tipos de OA, destacam-se nesta pesquisa, as simulações e animações, definidas por Moreira (2014, p. 52), como:

Programas menores, com modelos de um sistema ou processo voltado para sua visualização, apresenta um conjunto de exercícios ou questões para o aluno resolver, jogos educacionais que permitam ao aluno desenvolver a habilidade de testar hipóteses desafiando sua imaginação e criatividade e tutorial que ensina ao aluno determinado conteúdo através de sons e imagens, proporcionando uma forma mais dinâmica e animada de aprender.

Usados no cotidiano da sala de aula, as simulações podem ser empreendidas para apresentar, reforçar ou ilustrar conceitos de um determinado conteúdo ou tema. Fato conformado por Tavares (2008), para o qual, elas podem ilustrar o desenvolvimento instantâneo de um modelo, possibilitando a exposição temporal de um modelo abstrato em uma representação concreta. Sendo então, eficazes para demonstrar processos que são invisíveis à olho nu, como por exemplo, na ilustração de conceitos como cromossomos, genes, Ácido Desoxirribonucleico (DNA), meiose, probabilidade, mapeamento genético, entre outros.

Gianotto (2016, p. 12) corrobora neste sentido, ao afirmar que conceitos relativos à divisão celular, à duplicação do DNA e a síntese de proteínas podem ser melhor compreendidos por intermédio da apresentação e exploração de simulações. Para a autora, "nos softwares, como as simulações, por exemplo, estão presentes uma gama de recursos visuais que podem ser utilizados no ensino e aprendizagem de Ciências e Biologia".

Por conseguinte, esses programas educacionais disponibilizam um ambiente oportuno para a:

Realização de tarefas, revisão de conteúdos, desenvolvimento de novas habilidades e construção de saberes". Além de estimularem a aprendizagem, apresentando conteúdos de forma interativa e criativa, por meio de um ambiente agradável, buscando sempre respeitar os diferentes estilos e níveis de ensino e aprendizagem (Moreira, 2018, p. 29).

Ainda, Gianotto (2016, p.19) defende que o uso de softwares na educação "só faz sentido se contribuir para que o aluno possa construir conhecimentos a partir da compreensão do conteúdo abordado". Dessa forma, "escolhidos acertadamente, utilizados de acordo com uma metodologia adequada e aproveitando-se as características do recurso, os softwares de exercício e prática, jogos, simulações e tutoriais podem ser utilizados também nas aulas de Ciências e Biologia”.

Todavia, todo e qualquer recurso tecnológico deve ser usado com cuidado, o que requer conhecimento e planejamento sobre o uso do mesmo. Gianotto (2016, p.24) nos alerta que "o uso de simulações, por si só, não cria a melhor situação de aprendizado, devendo ter como complemento apresentações formais, leituras e discussões em sala de aula. [...]”. Dessa forma, esclarece ainda, que "como qualquer recurso didático, os softwares podem ser utilizados nas aulas de Ciências e Biologia, em momentos apropriados, com o professor alternando diferentes recursos, dependendo dos objetivos a serem atingidos em cada aula [...]". A autora explica ainda o quanto o uso das simulações pode ampliar a imaginação, a intuição e a visualização de um fenômeno vivenciado no cotidiano do aluno:

No estudo com simulações, ao imaginar e intuir o aluno pode ampliar a sua visão de um fenômeno ou situação e, assim, construir um conhecimento mais prático para ser usado em seu cotidiano. Embora as simulações não sejam dependentes da existência do computador, é nesse ambiente que se permite ao aluno manipular variáveis e observar resultados imediatos, decorrentes da modificação de situações e condições. Conceitos biológicos, físicos, geográficos, linguísticos e matemáticos, e muitos outros, podem tornar-se mais perceptíveis quando explorados esses atributos do recurso (Gianotto, 2016, p. 23).

Contudo, de acordo com a autora, é questionável a qualidade de diversos softwares comerciais, pois simulações de qualidade são muito complicadas de serem criadas, porque exigem uma produção técnica, além da competência dos 
professores, com recursos computacionais, gráficos e sonoros, normalmente não utilizados em seu cotidiano.

\subsection{Repositórios}

Repositórios são, segundo Brasil (2020), depósitos virtuais, ou seja, banco de dados, nos quais ficam alocados os OA, ou seja, materiais com fins educacionais, sendo possível realizar buscas por tema, área de conhecimento ou níveis de ensino, entre outros aspectos.

Os repositórios geralmente são mantidos por universidades, órgãos governamentais ou empresas, entre eles, os principais são: o Portal do Professor, a Rede Interativa Virtual de Educação - RIVED e o Banco Internacional de Objetos Educacionais, todos do Ministério da Educação - MEC; e o Portal Dia a dia Educação, mantido pela Secretaria da Educação do Estado do Paraná - SEED. Todos disponibilizam acervos digitais de imagens, vídeos, animações, simuladores, textos, jogos, fragmentos de filmes, entre outros.

Dentre os repositórios nacionais de OA, pode-se destacar o RIVED, mantido pela Secretaria de Educação a Distância (SEED) do Ministério da Educação (MEC). Trata-se de um portal, no qual, é disponibilizado uma grande variedade de OA, na forma de animações, que oportuniza a interação e a investigação de fenômenos químicos, físicos e biológicos, tendo em vista que, "possibilitam ao professor ilustrar a explicação, reforçar conceitos, levantar hipóteses e debates tornando o processo ensino-aprendizagem mais dinâmico" (Brasil, 2012, p. 1). Seu propósito é fornecer conteúdos digitais, na forma de OA, visando estimular o raciocínio e o pensamento crítico dos alunos, aliados à potencialidade inerente de novas abordagens pedagógicas da informática, possibilitando a aprendizagem e a formação do cidadão reflexivo e atuante.

O Banco Internacional de Objetos Educacionais (BIOE), mantido também pela SEED/MEC, consiste num repositório com objetos educacionais em vários formatos, nas diferentes áreas do conhecimento de todos os níveis de ensino. Esse repositório tem por objetivo, conforme Audino e Nascimento (2010, p. 139), "localizar, catalogar, avaliar e disponibilizar objetos educacionais digitais elaborados em diversas mídias nas áreas de conhecimentos previstas pela educação infantil, básica, profissional e superior". O Portal do Professor, também do MEC, em parceria com o Ministério da Ciência e Tecnologia, visa apoiar os processos de formação dos professores, enriquecendo sua prática pedagógica.

O Portal Dia a dia Educação, mantido pela Secretaria da Educação do Estado do Paraná, disponibiliza um acervo de simuladores, animações, áudios, imagens, jogos, vídeos e trechos de filmes das diversas áreas do conhecimento e níveis de ensino.

Por isto, cabe ao docente utilizar a seu favor esse processo de interação do educando com as mídias, valendo-se da grande quantidade de vídeos, imagens, animações, simulações, jogos na internet e AVA que podem ser utilizados como recursos didáticos nas aulas de Ciências e Biologia. Logo, o professor deverá adotar "novas metodologias de ensino, qualificar suas aulas, buscar e utilizar novos recursos tecnológicos” (Araújo, 2016, p. 15).

\subsection{TIC no ensino de Ciências e Biologia}

No contexto atual, o aprendizado das Ciências, não se limita apenas "ao uso de ferramentas tradicionais, como lápis, cadernos e livros, assim como dos espaços da sala de aula, mas incorpora-se à vida dos alunos através da televisão, do vídeo game, do computador, do celular e da internet com sua rede digital [...]" (Gianotto, 2016, p. 11). Fica assim evidente, que as TIC propiciaram transformações significativas para a educação, sendo perceptível, o quanto "vídeos, programas educativos na televisão e no computador, sites educacionais, softwares diferenciados transformam a realidade da aula tradicional, dinamizam o espaço de ensino e aprendizagem, onde, anteriormente, predominava a lousa, o giz, o livro e a voz do professor" (Kenski, 2012, p. 46).

No ensino de Ciências e Biologia, é imprescindível o uso de imagens, simulações, vídeos, entre outros, mesmo porque 
nem sempre é possível, manipular certos materiais, demonstrar determinadas reações ou observar alguns organismos. Gianotto (2016) enfatiza que estas ferramentas, de certa maneira, associam a aprendizagem ao elemento visual. As TIC na atualidade, reforçam Coll e Monereo (2010), são instrumentos que colaboram para uma aprendizagem fundamentada na representação visual do conhecimento.

Consequentemente, no ensino da Biologia, os recursos educacionais podem ser utilizados para "simular fenômenos da natureza, que normalmente são ensinados através de desenhos, sucatas, construção de maquetes e muita imaginação" (Gianotto, 2016, p. 23). A autora afirma ainda, que conceitos relativos à divisão celular, à duplicação do Ácido Desoxirribonucleico (DNA) e a síntese de proteínas podem ser melhor compreendidos por intermédio da apresentação e exploração de simulações. Portanto, "no ensino, a associação oral-visual é a forma que proporciona maior retenção de dados, e explorar o computador, aliando-o à oralidade do professor, pode contribuir significativamente para a produção de conhecimentos" (Gianotto, 2016, p. 16).

Na disciplina de Biologia, especificamente, o emprego de imagens, simulações, vídeos, é um recurso imprescindível, uma vez, que "uma parcela significativa das informações em Biologia é obtida por meio da observação direta dos organismos ou fenômenos ou por meio de observação de figuras, modelos, etc" (Krasilshick, 2008, p. 61). Assim, quando não é possível observar o organismo diretamente, o professor pode utilizar OA, seja na forma de trechos de vídeos, simuladores, jogos virtuais, animações entre outros para introduzir, ilustrar ou reforçar determinados conceitos. Nesse sentido, "além do livro didático, outros recursos metodológicos, se utilizados de maneira adequada e com finalidades pedagógicas, podem ser usados para despertar a atenção e instigar a criatividade e a curiosidade dos alunos, tais como filmes, fotografias, revistas, vídeos e computadores" (Gianotto, 2016, p. 15).

As Diretrizes Curriculares da Educação Básica - DCE, da disciplina de Biologia, indicam ao professor a utilização de imagens, vídeos, transparências, fotos e textos de apoio, mas enfatizam a necessidade da problematização e da interpretação, recomendando "analisar quais os objetivos e expectativas a serem atingidas, além da concepção de ciência que se agrega às atividades que utilizam estes recursos, pode contribuir para a compreensão do papel do aluno frente a tais atividades" (Paraná, 2008, p. 65).

As diretrizes de Biologia ressaltam ainda, a importância de o professor adotar estratégias metodológicas diversificadas, tais como aula dialogada, a leitura, a escrita, a atividade experimental, o estudo do meio, os jogos didáticos, entre outras, propiciando "a expressão dos aprendizes, seus pensamentos, suas percepções, significações, interpretações, uma vez que aprender envolve a produção/criação de novos significados, pois esse processo acarreta o encontro e o confronto das diferentes ideias propagadas em sala de aula" (Paraná, 2008, p.66).

A Base Nacional Comum Curricular implantada em 2018, apresentam 10 competências gerais que deverão abranger diariamente as atividades em sala de aula. Dentre essas competências, duas competências, a quarta e a quinta, contemplam o uso das tecnologias educacionais:

Utilizar diferentes linguagens - verbal (oral ou visual-motora, como Libras, e escrita), corporal, visual, sonora e digital -, bem como conhecimentos das linguagens artística, Matemática e científica, para se expressar e partilhar informações, experiências, ideias e sentimentos em diferentes contextos e produzir sentidos que levem ao entendimento mútuo. (Brasil, 2018, p.9).

E mais especificamente a quinta competência, aborda a cultura digital, visando compreender, utilizar e criar tecnologias digitais de forma crítica e ética, com o intuito de levar o aluno à: comunicar-se, acessar e produzir informações e conhecimentos, resolver problemas e exercer protagonismo e autoria (Brasil, 2018). Assim, 
Percebe-se que o principal documento norteador das aprendizagens essenciais que todos os alunos devem desenvolver ao longo da educação básica incentiva e ressalta a importância das TDICs na educação, como uma ferramenta para auxiliar no desenvolvimento de novas estratégias de aprendizagem, capaz de colaborar significativamente para o processo de construção do conhecimento, nas mais diversas áreas (Mesquita et al., 2021, p.3).

Neste sentido, corrobora Mastrela (2016), ao considerar a informática educacional um recurso didático essencial e de grande abrangência, uma vez que detêm uma grande variedade de recursos possibilitando "se comunicar, pesquisar, criar desenhos, efetuar cálculos, simular fenômenos e tantas outras ações”, além de auxiliar o aluno a aprender a informática básica a ser utilizada no meio social (Araújo, 2016, p. 27).

\subsection{TIC no ensino de Genética}

Ao ministrar a disciplina de Biologia, principalmente os conteúdos relativos à Genética, é possível perceber a dificuldade dos alunos na compreensão dos conceitos dessa ciência, tanto pelo alto nível de abstração presente, como pela dificuldade em interpretar textos, a falta de conhecimentos considerados pré-requisitos, como alguns conceitos da bioquímica e da Matemática, principalmente quanto ao conceito e aplicação da probabilidade. Isso se deve, pelo fato dos processos biológicos serem "caracterizados por uma grande complexidade, são difíceis de visualizar, permanecendo invisíveis a olho nu, de duração demasiado lenta ou rápida, exigindo ao aluno um nível de abstração assinalável na construção de modelos mentais para a sua compreensão, o que não é fácil” (Dias; Chagas, 2015, p.1). Essa dificuldade pode ocasionar desmotivação e desinteresse pela aprendizagem desse conteúdo, pois "o aluno acaba por se desmotivar, desinteressar e desistir de aprender" (Dias, Chagas, 2015, p.1).

No ensino de Genética, especialmente, o uso dos recursos tecnológicos é apropriado, pois "o seu ensino é complexo, é baseado em vocabulário próprio, com conceitos abstratos, que podem dificultar o aprendizado" (Rocha, 2016, 2001, p. 1). As dificuldades de se aprender conceitos, se devem, principalmente, por essa área apresentar "uma grande quantidade de termos, que se restringem apenas aos conhecimentos específicos da Biologia, e que não estão presentes no cotidiano dos alunos" (Araújo; Gusmão, 2017, p.2).

Para Cardoso e Oliveira (2010), além da complexidade de abstração do conteúdo existem outros obstáculos advindos "da exigência de um vocabulário muito específico, conhecimentos prévios sobre probabilidade e divisão celular" o que exige que o educando tenha esquematizado "uma rede de conceitos que envolvem a Biologia molecular, a bioquímica, cálculos elementares de probabilidade e uma série de exceções relativas à produção e aplicabilidade do conhecimento biológico" (Cardoso; Oliveira, 2010, p. 101).

Ainda, Borges et al. (2017), acrescenta que muitos conteúdos, mesmo despertando o interesse dos alunos, tornam-se incompreendidos por diferentes razões, como: vocabulário característico (complexo), termos específicos, cálculos matemáticos, etc. Fato este contemplado num estudo realizado por Temp e Bartholomei-Santos (2018) intitulado "O ensino de Genética: a visão de professores de Biologia", no qual identificam que, para a maioria dos professores pesquisados, "a dificuldade no aprendizado de Genética se relaciona ao excesso de terminologia, dificuldade de interpretação e relação com outros conteúdos e disciplinas" (Temp; Bartholomei-Santos, 2018, p. 1).

Diante dessas dificuldades, Cardoso e Oliveira (2010), salientam a necessidade de se propiciar aos educandos novas formas de aprender a Biologia que os auxiliem a resolver problemas do cotidiano, sobretudo contribuindo na "formação de conceitos de Genética e outras áreas, transcendendo o seu universo conceitual, para que o estudante possa transitar entre o conhecimento científico e o senso comum" (Cardoso, Oliveira, 2010, p. 107/108). Desse modo, é obrigação e competência da escola, trabalhar os conteúdos de Genética, de maneira integrada e sistêmica, oportunizando uma educação aos cidadãos que lhes promova a apropriação dos conhecimentos, lhes concedendo a fundamentação teórica necessária para tomar decisões 
(Leite, 2000).

Visto que, essa área da ciência é constantemente veiculada nos meios de comunicação, devido, sobretudo, aos avanços biotecnológicos, tais como o "consumo de vários alimentos transgênicos, bem como as discussões sobre terapia gênica, células tronco, genomas e clonagem" (Cardoso, Oliveira, 2010, p. 101-102) as mídias podem "apresentar-se como um dos principais meios de reprodução destes conhecimentos" (Reis et al., 2010, p.1).

Portanto, ressaltam Amabis e Martho (2001), com a evolução nos estudos científicos e a abordagem frequente do tema nos meios de comunicação, a Genética tem despertado maior interesse nos alunos do ensino médio, visto que o tema está relacionado ao seu cotidiano. Há ainda, a curiosidade dos mesmos em "compreender e explicar suas próprias características familiares" (Amabis; Martho, 2001, p. 184). Sendo assim, relacionar os conceitos desta área é relevante para que a "população possa entender o grande espectro de aplicações e implicações da Genética aplicada" (Cardoso, Oliveira, 2010, p. 102).

Nesse mesmo sentido, destaca que os conhecimentos biológicos, precisam ser compreendidos como produção histórica, sendo "indispensáveis à compreensão da prática social, podem contribuir para revelar a realidade concreta de forma crítica e explicitar as possibilidades de atuação dos sujeitos no processo de transformação desta realidade” (Libâneo, 1983).

\section{Metodologia}

A metodologia adotada nesta pesquisa é de natureza qualitativa, por meio da observação participante. Pois, esta metodologia tem o intuito de "aprofundar a compreensão dos fenômenos que investiga a partir de uma análise rigorosa e criteriosa desse tipo de informação" (Moraes \& Galiazzi, 2011, p.11).

Primeiramente foi realizada uma pesquisa bibliográfica sobre os recursos educacionais, tais como ambientes virtuais, especialmente o Google Sala de Aula e as simulações e sua contribuição no ensino de Genética. O referencial teórico consiste no "levantamento, seleção, fichamento e arquivamento de informações relacionadas à pesquisa" (Amaral, 2007, p.5).

Num segundo momento, implementou-se numa turma do $4^{\circ}$ ano do Curso de Administração nível médio de uma escola da rede pública do município de Paranavaí-PR, parte de uma sequência didática intitulada "Objetos de aprendizagem como recurso didático no processo ensino-aprendizagem de genética" (Bilthauer;Takasusuki, 2012), sobre a construção dos conceitos básicos de genética mendeliana (Quadro 1). A Sequência didática é compreendida como "um modo de o professor organizar as atividades de ensino em função de núcleos temáticos e procedimentais” (Araújo, 2013, p. 323). 
Quadro 1 - Simulações utilizadas na implementação.

\begin{tabular}{|c|c|c|}
\hline Simulação & Objetivo da Simulaçĩo & Objetivo na Propoata \\
\hline $\begin{array}{l}\text { Atividade } 1-0 \\
\text { Caso do rebanho } \\
\text { de Jaco }\end{array}$ & $\begin{array}{l}\text { Reconhecer que individuos que } \\
\text { apresentam un mesmo fenótipo podem } \\
\text { possuir genótipos diferentes. }\end{array}$ & $\begin{array}{l}\text { Apresentaçào dos conceitos de Genética clássica e de hereditariedade, por meio } \\
\text { de uma situaçăo problema do personagem biblico Jacó, com o objetivo de } \\
\text { reconhecer que individuos que apresentam um mesmo fenótipo, podem } \\
\text { apresentar genótipos diferentes, alèm de elaborar suposiçōes sobre o fenömeno } \\
\text { estudado. } \\
\text { Elaboraçăo de uma tabela utilizando o Google Planithas sobre os cruzameatos } \\
\text { e a quantidade de filhotes produzidos e suas respectivas cores. }\end{array}$ \\
\hline 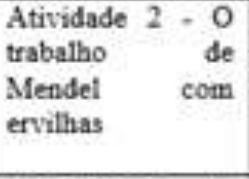 & $\begin{array}{l}\text { Identificar os genótipos e fenótipos, as } \\
\text { geraç̄̄es parentais, F1 e F2, os } \\
\text { heterozigotos e os homozigotos, no } \\
\text { problema apresentado. }\end{array}$ & 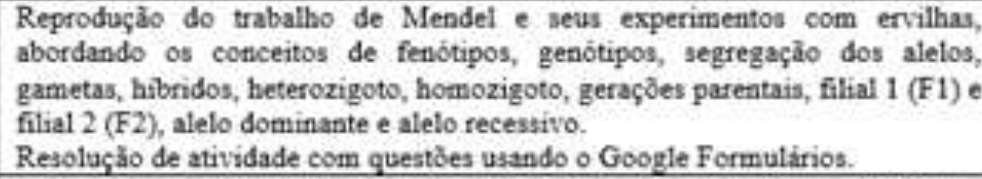 \\
\hline $\begin{array}{l}\text { Atividade } 3 . \text { As } \\
\text { ervilhas ajudariam } \\
\text { Jac6? }\end{array}$ & $\begin{array}{l}\text { Reconhecer se os individuos que } \\
\text { apresentam um mesmo fenotipo podem } \\
\text { expressar genótipos diferentes e propde } \\
\text { hipoteses sobre berança aplicando as } \\
\text { ideias de Meadel, alem de testar } \\
\text { hipotese sobre berança. }\end{array}$ & 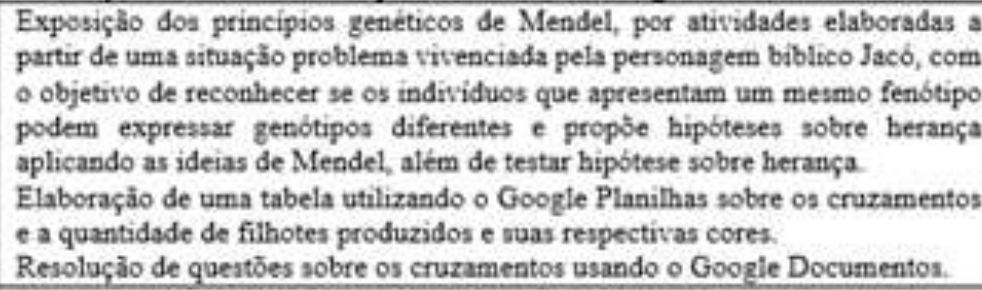 \\
\hline $\begin{array}{l}\text { Atividade } 4-E \\
\text { hora de colocar as } \\
\text { coisas no lugar. }\end{array}$ & $\begin{array}{l}\text { Relacionar os coaceitos de célula, gene, } \\
\text { alelos, DNA e cromossomo, elaborando } \\
\text { um mapa conceitual. }\end{array}$ & $\begin{array}{l}\text { Elaboração um mapa dos conceitos sobre zenes, cromossomos e DNA. } \\
\text { Inserção da atividade no Google Apresentaçōes; }\end{array}$ \\
\hline $\begin{array}{l}\text { Atividade } 5 \text { - } \\
\text { Mendel nåo sabia } \\
\text { disso. }\end{array}$ & $\begin{array}{l}\text { Elaborar uma sequèacia relacionando os } \\
\text { seguintes conceitos: hereditariedade, } \\
\text { DNA, mitose, meiose, sintese de } \\
\text { proteinas, etc. }\end{array}$ & $\begin{array}{l}\text { Elaboraçäo um pequeno video, a partir de imagens e legendas disponiveis em } \\
\text { uma tela, com o objetivo de estabelecer uma sequéncia aos processos bisicos } \\
\text { da hereditariedade, tais como a mitose, a meiose e a sintese de proteinas. }\end{array}$ \\
\hline $\begin{array}{l}\text { Atividade } 6- \\
\text { Vendo o mundo } \\
\text { com outros olhos }\end{array}$ & $\begin{array}{l}\text { Compreender situaçóes especiais de } \\
\text { genea recessivos ligados aos } \\
\text { cromosscmos sexuass, especialmente os } \\
\text { situados no cromossomo } \mathrm{X} \text {, como o } \\
\text { daltonismo. }\end{array}$ & $\begin{array}{l}\text { Explanaçăo sobre berança ligada aos cromossomos sexuais, especialmente os } \\
\text { situados no cromossomo X, como o daltonismo } \\
\text { Resoluçào de atividade relacionando as caracteristicas fenotipicas e genotipicas } \\
\text { de indrviduos daltónicos e cálculo das probabilidades de ocorrència do } \\
\text { daltonismo a partir de uma situaça ào problema do cotidiano. }\end{array}$ \\
\hline
\end{tabular}

Fonte: Autores (2020).

A implementação da pesquisa teve início no dia 12 de março de 2019 e finalizou em 04 de junho de 2019, sendo realizada no primeiro trimestre deste ano letivo, aplicada em 12 encontros semanais, com duração de 50 minutos, realizadas no próprio turno durante as aulas de Biologia.

Para a sua aplicação, optou-se pela elaboração de uma plataforma virtual pois, além de abrir nos computadores da sala de informática da própria escola, ela também dispõe do formato aplicativo, sendo possível acessá-la em celular, nos diversos sistemas operacionais. Por ser um ambiente virtual, possibilitou à pesquisadora a construção passo-a-passo de seu conteúdo, explicações e instruções pertinentes. Valente (2009) denomina esse sentimento de empowerment, segundo o qual quando é dada a oportunidade para a pessoa compreender o que está elaborando, este tem a sensação de ser capaz de produzir algo considerado impossível.

Para a execução da proposta criou-se um ambiente virtual na plataforma Google Sala de Aula, a partir da qual, implementou-se a referida sequência didática, com a inserção de textos e atividades, explorando animações, simulações e vídeos sobre os conceitos básicos de genética. Por meio deste ambiente, explorou-se recursos como a apresentação de conteúdo, proposições de atividades, questões, instrumentos de avaliação e formas de interação como chats.

Após a implementação da sequência didática, aplicou-se um questionário pós-teste, elaborado pela autora, com dezesseis questões mistas (objetivas e subjetivas, com intuito de investigar junto aos alunos as contribuições, potencialidade e dificuldades das simulações trabalhadas para o processo ensino e aprendizagem de Genética. Para este artigo foram selecionadas três, cujo os resultados são apresentados na sequência. 


\section{Resultados e discussão}

Neste tópico apresentamos os resultados e discussão acerca das contribuições, potencialidades e dificuldades do uso de simulações para o processo ensino e aprendizagem de Genética, de acordo com os alunos do $4^{\circ}$ ano do Curso de Administração Integrado em uma escola da rede pública do município de Paranavaí.

Ao serem indagados sobre a importância do uso dos recursos tecnológicos, tais como as simulações, como forma de facilitar a aprendizagem dos conceitos de Genética, quatorze alunos indicaram sim, ser importante; sendo que para dez, facilitam a aprendizagem e para quatro, possibilitam a diversificação metodológica ao empregar os recursos tecnológicos; e para um aluno não é importante, pois há uma dificuldade de aprendizagem (Gráfico 1).

Gráfico 1 - A importância do uso de recursos tecnológicos, tais como simulações, como forma de facilitar a aprendizagem dos conceitos de Genética.

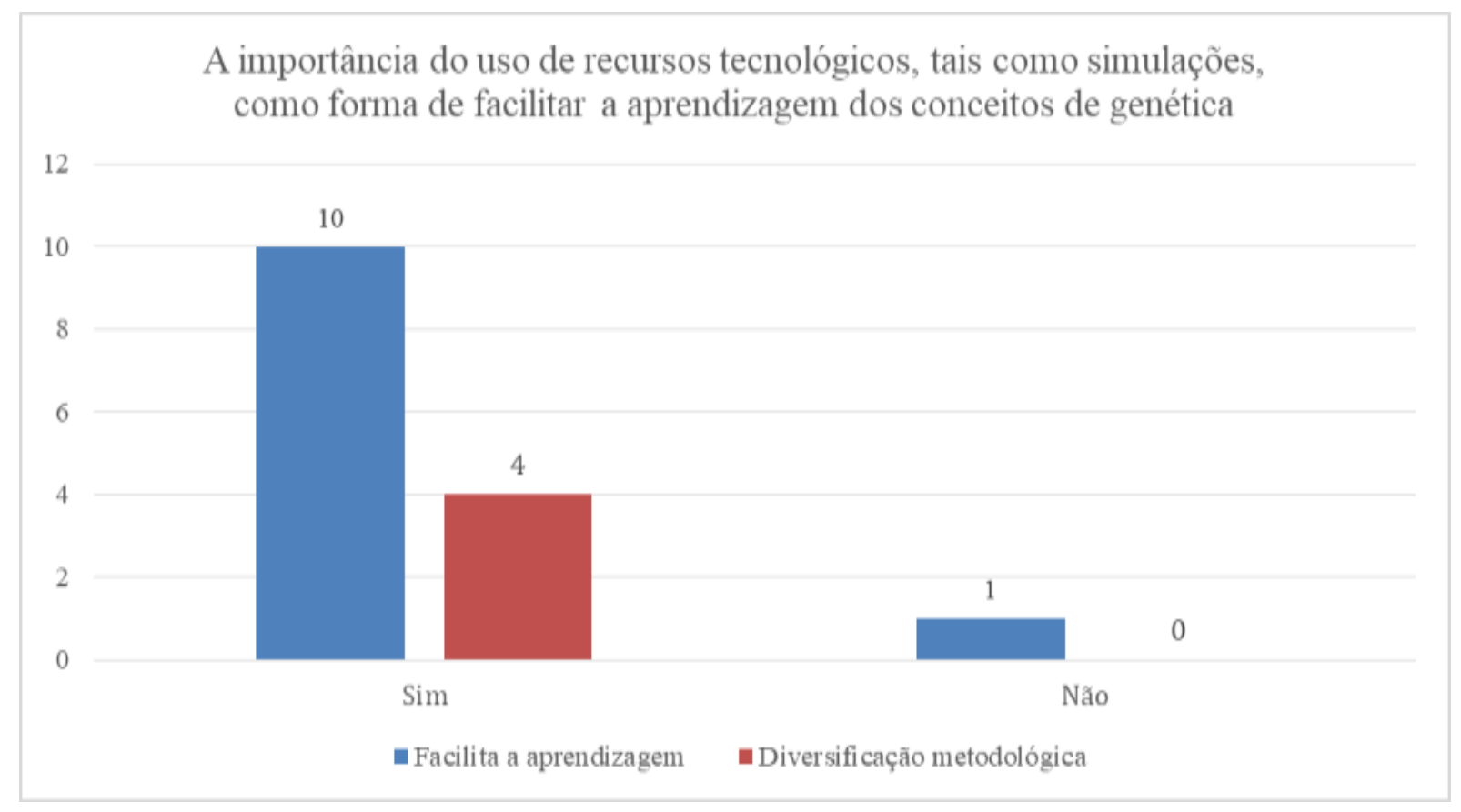

Fonte: Autores (2020).

De acordo com esses dados, ressalta-se que quatorze alunos acreditam que sim, que o uso dos recursos é importante para a aprendizagem significativa de Genética. Sendo que para dez alunos isso ocorre pelo fato de facilitar a aprendizagem. Souza e Souza (2016, p. 11) corroboram nesse sentido, afirmando que "as novas tecnologias são capazes de facilitar o ensino e aprendizagem no âmbito educacional, agilizando a troca de informações e produzindo conhecimento compartilhado entre os alunos e o professor". Fato este que pode ser confirmado nas falas dos alunos A3, A4, A6, A7, A9, A10, A11, A13 e A15.

Conforme Audino e Nascimento (2010), os OA são relevantes no processo ensino e aprendizagem, por vários motivos, entre os quais: apresentam baixo custo de produção, nos possibilitam simular e animar fenômenos, sendo reutilizáveis em diferentes AVA, dessa forma, ficando alocados em repositórios virtuais disponíveis na internet.

Para quatro alunos, a utilização de recursos educacionais, como as simulações são importantes, pois possibilitam uma diversificação metodológica com uso dos recursos tecnológicos. Assim, por "ser reutilizável e estimular a criatividade e imaginação do aprendiz, eles enriquecem a prática do professor em sala de aula e facilitam a compreensão dos alunos" (Aandrade; Scareli, 2011, p. 5).

Dentre estas metodologias, estão as chamadas metodologias ativas, muito discutidas na atualidade, nas quais "o 
aprendizado se dá a partir de problemas e situações reais; os mesmos que os alunos vivenciarão depois na vida profissional, de forma antecipada, durante o curso" (Moran, 2015, p. 29). Estas podem contemplar o uso de recursos como simulações e AVA, como o próprio Google Sala de Aula.

Assim, seu uso pode se tornar enriquecedor, pois "pode despertar o interesse do aluno por meio de um trabalho lúdico e prazeroso, que o levará a uma maior socialização e um processo de relacionamento interpessoal, o qual propiciará o aprendizado coletivo" (Araújo, 2016, p. 17). Fato esse constatado pelo aluno A14, ao afirmar que "Sim, pois apresentam animações uma qualidade melhor, que nos permitem uma forma de interação mais descontraída e inovadora".

Neste item, apenas um aluno julga que o uso de recursos tecnológicos, tais como simulações, não são importantes como forma de facilitar a aprendizagem dos conceitos de Genética, pois para ele gera uma dificuldade de aprendizagem, pois considera o método tradicional de ensino mais fácil de aprender. Percebe-se uma certa resistência de adaptação a metodologia adotada, por certo, decorrente de anos adotando um método tradicional.

Sobre os aspectos positivos da utilização de simulações para a aprendizagem de Genética, nove alunos indicaram facilitar a aprendizagem; três mencionaram a organização e praticidade dos recursos; um apontou o fato de tornar a aula mais dinâmica; um ressaltou o aspecto das ilustrações; e um assinalou a facilidade de acesso (Gráfico 2).

Gráfico 2 - Aspectos positivos da utilização de simulações para a aprendizagem de Genética.

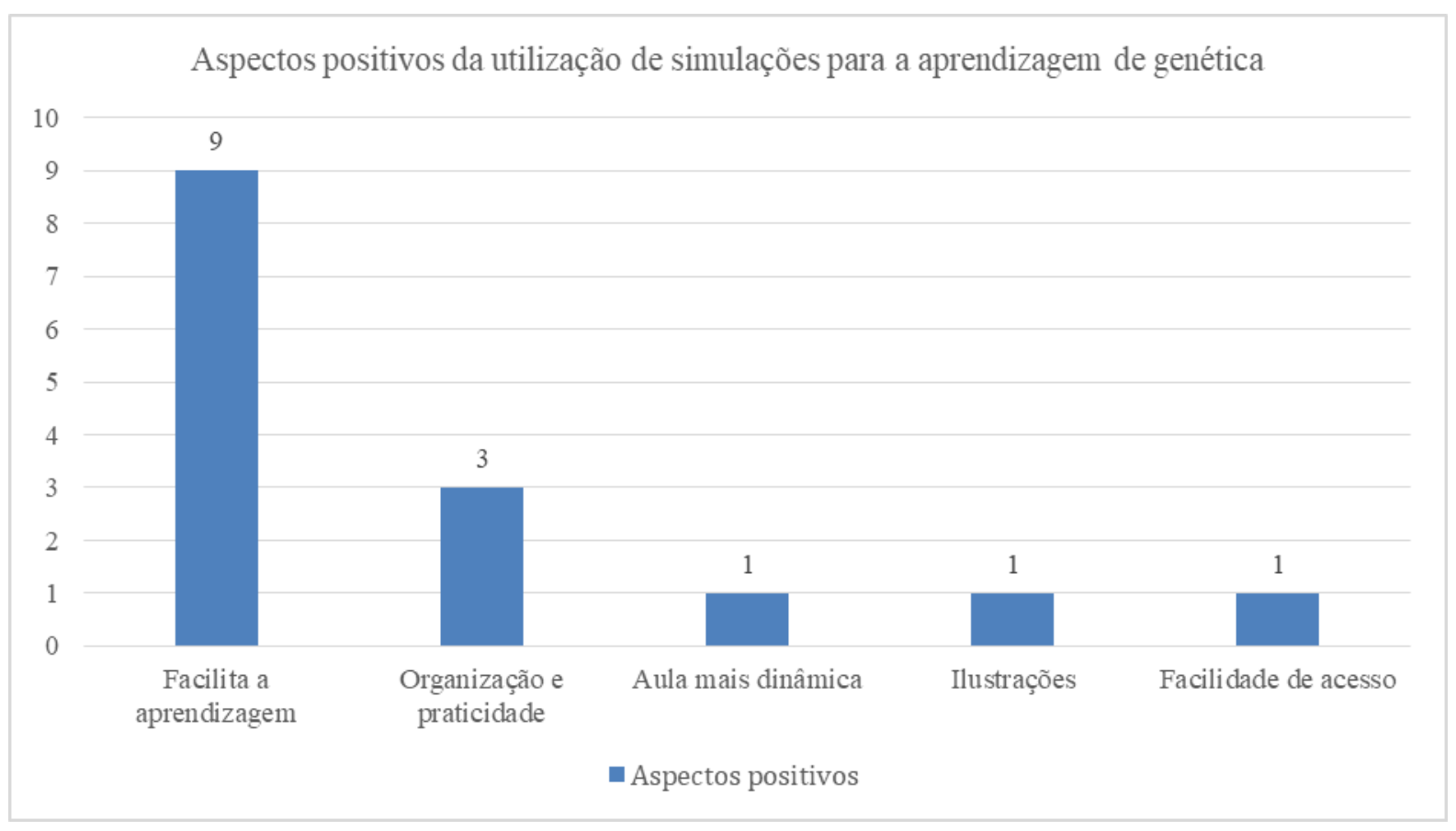

Fonte: Autores (2020).

O uso de simulações também pode ser facilitador de uma aprendizagem significativa e contemplar uma metodologia ativa, pois segundo Tavares (2008), elas auxiliam a explicar determinados fenômenos da natureza; simulam a dinâmica de determinada realidade; podem auxiliar na construção de um modelo acadêmico intermediário entre o que o aluno já conhece e o produto final a ser alcançado; representa a evolução temporal da realidade, podendo controlar a velocidade dos fenômenos; podem ser utilizadas para visualizar processos não visíveis ao olho nu, tais como o movimento do ar ou um algoritmo; entre outros. Dessa forma, no uso das simulações no processo pedagógico, "o aluno pode adequar a ferramenta instrucional ao seu estilo de aprendizagem e sua estrutura cognitiva'. (Tavares, 2008, p. 105). O autor acrescenta ainda que, "a medida em que 
interage com a informação, o estudante está construindo seu conhecimento, ele faz conexões importantes entre significados e desse modo possibilita a sua aprendizagem significativa. (Tavares, 2008, p. 106-107).

Dessa maneira, o uso de simulações de forma bem planejada, podem facilitar a aprendizagem pois,

Em geral, esses programas educativos oferecem um ambiente favorável para a realização de tarefas, revisão de conteúdos, desenvolvimento de novas habilidades e construção de saberes. Além de estimularem a aprendizagem, apresentando conteúdos de forma interativa e criativa, por meio de um ambiente agradável, buscando sempre respeitar os diferentes estilos e níveis de ensino e aprendizagem (Moreira, 2018, p. 29).

Nesse mesmo sentido, Macêdo (2012, p. 575) contribui que as simulações podem ser usadas "ao finalizar um tema, para identificar possíveis falhas na aprendizagem e saná-las, ou ainda antes de introduzir determinado conceito, como forma de obter-se um diagnóstico prévio dos pré-conceitos dos estudantes sobre o tema a ser estudado".

Por certo, as simulações, se utilizadas de forma bem estruturada e planejada podem facilitar a aprendizagem proporcionando organização e praticidade na apresentação dos conceitos e execução das atividades, tornando consequentemente a aula mais dinâmica. Assim sendo, seu uso possibilita reorganizar as práticas pedagógicas, propiciando novas reflexões sobre o uso dos recursos da comunicação, da informação e da interação. Assim, associados com outras mídias digitais podem garantir "situações de aprendizagem em que o educador assuma o caráter de mediador e o aluno o caráter de sujeito ativo dentro do processo de ensino e aprendizagem" (Audino; Nascimento, 2010, p. 131).

No tocante à ilustração, as simulações são utilizadas no cotidiano da sala de aula para apresentar, reforçar ou ilustrar conceitos de um determinado conteúdo ou tema. Fato confirmado por Tavares (2008), para o qual, elas podem ilustrar o desenvolvimento instantâneo de um modelo, possibilitando a exposição temporal de um modelo abstrato em uma representação concreta. Sendo então, eficazes para demonstrar processos que são invisíveis à olho nu, como por exemplo, em Genética, na ilustração de conceitos como cromossomos, genes, DNA, meiose, probabilidade, mapeamento, entre outros. Portanto, um objeto de aprendizagem, precisa ser atraente, tendo um designer que colabore para a "elaboração de um ambiente virtual envolvente que instigue o aluno a investigar, fazer questionamentos, relacionar fatos e aplicar conhecimentos" (Nascimento, 2007, p. 139).

A facilidade de acesso, por sua vez, se deve ao fato destes objetos serem reutilizáveis, sendo relevantes no processo ensino e aprendizagem. A reusabilidade, acrescenta os autores, é considerada a sua principal característica, permitindo o uso em diferentes AVA, por meio de repositórios nos quais os OA ficam alojados e catalogados, possibilitando a busca por temas, por nível de dificuldade, por autor ou por relação com outros objetos similares. Desse modo, por "ser reutilizável e estimular a criatividade e imaginação do aprendiz, eles enriquecem a prática do professor em sala de aula e facilitam a compreensão dos alunos" (Andrade; Scareli, 2011, p. 5).

No que tange aos aspectos negativos da utilização de simulações para a aprendizagem de Genética, sete alunos afirmaram ter sentido dificuldade de compreender a atividade; cinco consideraram complexa a execução propriamente dita das atividades; dois alunos citaram como maior obstáculo o acesso à internet; e um aluno mencionou como desfavorável a ilustração, devido à baixa qualidade na aparência das simulações (Gráfico 3). 
Gráfico 3 - Aspectos negativos da utilização de simulações para a aprendizagem de Genética.

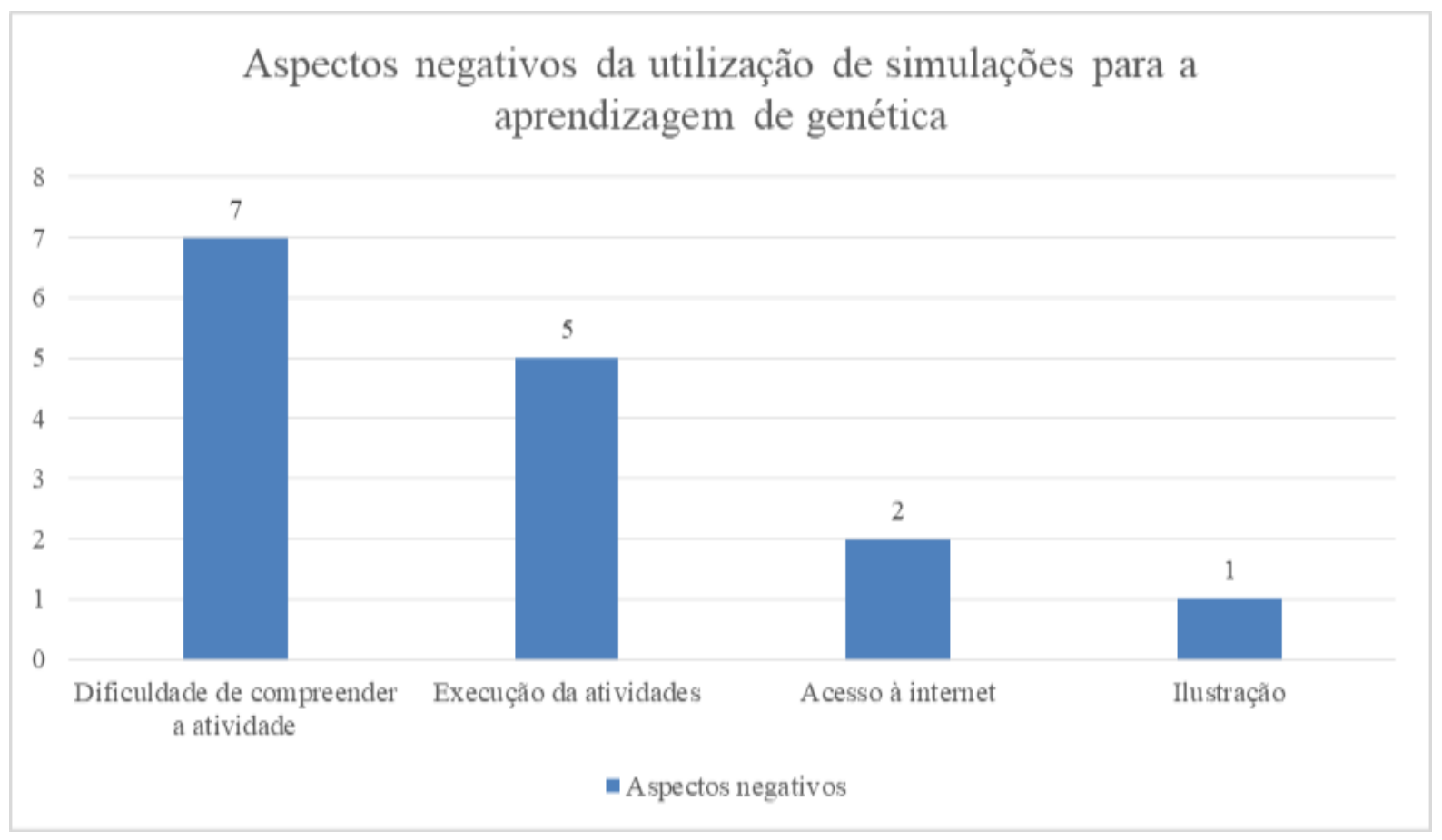

Fonte: Autores (2020).

Segundo Nascimento (2007), as simulações devem apresentar uma linguagem e orientações claras sobre o desenvolvimento das atividades. Esse é um fator imprescindível para que não ocorram obstáculos, como os citados por sete alunos que sentiram dificuldade em entender as atividades em aspectos como sua linguagem e compreensão de suas propostas; e cinco alunos, que tiveram problemas na sua execução, em aspectos como salvar, entre outros.

Gagné et al. (2005), recomenda que o conteúdo de um objeto de aprendizagem tenha uma metodologia de apresentação adequada ao conteúdo explorado, o que influencia diretamente a percepção do aluno. Essa apresentação deve possuir uma orientação e organização de tal forma que o aluno não se sinta perdido, conduzindo o educando na construção do conhecimento, seja por meio de enunciados, sugestões, figuras, situações problemas, entre outros. Essa orientação deve ser elaborada levando em consideração a sequência do conteúdo, sendo que as atividades devem fornecer dicas durante a aprendizagem e feedbacks para reforçar a aprendizagem.

Como mencionado anteriormente, a dificuldade de acesso à internet pode ser um grande empecilho na utilização destes recursos, uma vez que demandam a realização de downloads prévios ou carregá-los no momento da execução da aula, o que requer uma boa velocidade de internet. Conforme Stinghen (2016, p. 11), esse é um obstáculo bastante forte para o uso das tecnologias, pois "nem todos os alunos têm computador, além disso, muitas vezes o acesso à internet é restringido pela velocidade ou pela disponibilidade de tempo". Fato este vivenciado na implementação desta sequência didática.

A ilustração, por sua vez, como mencionada pelo aluno A12, ao considerar as simulações de baixa qualidade na aparência como um ponto negativo para aprendizagem, é um aspecto a ser considerado sobre o design do objeto de aprendizagem, que consiste nos "elementos de composição (textos, gráficos, imagens, dentre outros) como parte integrante do material digital, a fim de proporcionar a instigação do usuário por meios lúdicos, fazendo-o buscar o conhecimento além do básico" (Silva, 2017, p. 3). Portanto, cabe ao docente "avaliar o objeto de aprendizagem mais adequado e adaptado às necessidades, conhecimento, habilidades e os contextos de aprendizagem para cada faixa etária” (Machado et al., 2011, p. 95). 


\section{Conclusão}

A sociedade contemporânea é marcada por um grande avanço tecnológico, principalmente nos recursos midiáticos, na transmissão de informações e consequentemente, na construção do conhecimento. Isso requer da escola um papel de formação para a inclusão dos alunos nessa linguagem tecnológica, até mesmo para que possam atuar como profissionais e cidadãos. E consequentemente, contribuir com essa preparação ao ensinar o aluno a usar recursos que o auxiliem na busca por informações e conhecimentos e a ter senso crítico para filtrar informações que realmente sejam verídicas.

Por certo, o uso dos recursos tecnológicos, tais como as simulações são relevantes, pois facilitam a aprendizagem, diversificam a metodologia, possibilitam a organização e praticidade, tornando as aulas mais dinâmicas. No entanto, possuem aspectos que precisam ser revistos e reorganizados para a melhoria da aplicação desses recursos, tais como: dificuldade de compreender a atividade; complexidade na execução das atividades; o acesso à internet; e a baixa qualidade na aparência das simulações, que precisam ser melhorados.

Por conseguinte, a utilização dos recursos tecnológicos como as simulações, oportuniza a interação, a discussão, o aprofundamento de determinados temas, conteúdos e conceitos nas mais diversas áreas do conhecimento, incluindo Biologia e Genética. São recursos tecnológicos que auxiliam na mediação professor/aluno para o processo ensino e aprendizagem, contribuindo na investigação dos conhecimentos prévios dos alunos, na elaboração de conceitos e do conhecimento, bem como, na transposição para o conhecimento científico.

Em síntese, quanto às contribuições, potencialidade e dificuldades das simulações para a aprendizagem significativa de Genética, se pode perceber afirmar que a maioria dos alunos consideraram importante o uso dos recursos tecnológicos, tais como simulações, pois facilitam a aprendizagem dos conceitos de Genética e possibilitam a diversificação metodológica. Entre os aspectos positivos apontados pelos alunos estão: facilitar a aprendizagem, a organização e praticidade dos recursos; tornar a aula mais dinâmica; a ilustração e a facilidade de acesso. Em termos de relevância, a maioria dos alunos consideraram relevantes as simulações trabalhadas. Entre os aspectos negativos da utilização de simulações para a aprendizagem de Genética, os alunos indicaram: dificuldade de compreender a atividade; complexidade na execução das atividades; o acesso à internet; e a baixa qualidade na aparência das simulações.

Ressaltamos que o uso desses recursos tecnológicos pode ser muito relevante, didaticamente, se for utilizado de maneira planejada, pois facilitam a aprendizagem, diversificam a metodologia, possibilitam a organização e praticidade, tornando as aulas mais dinâmicas. Por serem trabalhadas a partir de uma situação problema, elas estimulam a interação e o raciocínio dos alunos, tornando-os mais críticos.

Por fim, acreditamos que uma das possibilidades de continuação da pesquisa seria a replicação para os demais professores da rede, na forma de oficinas ou grupos de estudos dos conhecimentos sobre a utilização das simulações como estratégia didática adquiridos durante a realização desta pesquisa.

\section{Referências}

Amabis, J. M., \& Martho, G. R. (2001) Guia de apoio didático para os três volumes da obra conceitos de Biologia: objetivos de ensino, mapeamento de conceitos, sugestões de atividades. Moderna.

Amaral, J. F. (2007). Como fazer uma pesquisa bibliográfica. Faculdade de Medicina, Universidade Federal do Ceará. https://cienciassaude.medicina.uf g.br/up/150/ o/Anexo_C5_Como_fazer_pesquisa_bibliografica.pdf.

Anadrade, J. G, \& Scareli, G. (2011). Rived e suas potencialidades na educação: os objetos de aprendizagem em questão. V Colóquio Internacional "Educação e Contemporaneidade". São Cristóvão-SE, http://www.educonufs.com.br/vcoloquio/cdcoloquio/cdroom/eixo \%208/PDF/Microsof t\%20Word\%20-\%20RIVED\%20E\%20SUAS\%20POTENCIALIDADES\%20NA\%20EDUCAcaO\%20OS\%20OBJETOS\%20VIRTUAIS\%20DE\%20 APR EN DIZAGEM\%20EM\%20QUESTaO.pdf.

Araújo, A. B., \& Gusmão, F. A. F. (2017). As principais dificuldades encontradas no ensino de Genética na educação básica brasileira. https://eventos.set.ed u.br/index.php/enfope/article/download/4710/1566. 
Araújo, D. L. (2013). O que é (e como faz) sequência didática? Entrepalavras, Fortaleza - ano 3, 3(1), 322-334, http://www.entrepalavras.ufc.br/revis ta/index.php/Revista/article/view/148/181

Araújo, H. M. C. (2016). O uso das ferramentas do aplicativo "Google sala de aula" no ensino de Matemática. 93 f. Dissertação (Programa de Mestrado Profissional em Matemática) - Universidade Federal de Goiás, Catalão. https://repositorio.bc.ufg.br/tede/handle/tede/6470?mode=full\#preview-link0.

Audino, D. F., \& Nascimento, R. S. (2010). Objetos de Aprendizagem - diálogos entre conceitos e uma proposição aplicada à aprendizagem. Revista contemporânea de Educação, 5(10). http://www.revistacontemporanea.fe.ufrj.br/index.php/contemporanea/article/view/122

Bilthauer, M. I., \& Takasusuki, M. C. C. R. (2012) Objetos de aprendizagem como recurso didático no processo ensino-aprendizagem de Genética. In: $O$ professor PDE e os desafios da escola pública paranaense. www.diaadiaeducacao.pr.gov.br/portals/cadernospde/pdebusca/producoes _pde/2012/2012_uem_bio_artigo_marisa_ines_bilthauer.pdf.

Brasil. Ministério da Educação. (2018) Base Nacional Comum Curricular. http://basenacionalcomum.mec.gov.br/images/BNC C_EI_EF_110518_versaofinal_site.pdf.

Brasil. Ministério da Educação. (2020). Programa Linux Educacional: Objetos de Aprendizagem. http://webeduc.mec.gov.br/linuxeducac ional/curso_le/modulo4_4_1.html.

Brasil. Ministério da Educação. Secretaria de Educação a Distância. (2012) Rede interativa virtual de educação - RIVED. http://rived.mec.gov.br/site_objeto_lis.php.

Borges, C. G. D. et al. (2017). As dificuldades e os desafios sobre a aprendizagem das leis de Mendel enfrentados por alunos do Ensino Médio. Experiências em Ensino de Ciências. 12(6). https://if.ufmt.br/eenci/artigos/Artigo_ID403/v12_n6_a2017.pdf.

Cardoso, L. R., \& Oliveira, V. S. (2010). O uso das tecnologias da comunicação digital: desafios no ensino de Genética mendeliana no ensino médio. Informática na Educação: teoria \& prática. 13(1), 101-114.

Coll, C., \& Monereo, C. (2010). Psicologia da educação virtual: aprender e ensinar com as tecnologias da informação e da comunicação. Artmed.

Dias, C. P., \& Chagas, I. (2019). Multimídia como recurso didático no ensino da Biologia. Interacções. (39), 393-404. https://revistas.rc aap.pt/interaccoes/article/view/8746/6305

Gagné, R et al. (2005). Princípios de design instrucional. Thomson Wadsworth, 2005.

Gianotto, D. E. P. (2016). Possibilidades, contribuições e desafios das ferramentas da informática no ensino das Ciências. Curitiba: CRV.

Hamze, A. (2011). As TICS na prática Pedagógica. https://educador.brasilescola.uol.com.br/trabalho-docente/as-tics-na-pratica-pedagogica.htm.

Kenski, V. M. (2012). Educação e tecnologias: o novo ritmo da informação. Papirus.

Krasilchik, M. (2008). Prática de ensino de Biologia. (4a ed.), Editora de São Paulo.

Leite, B. (2000). Biotecnologias, clones e quimeras sob controle social: missão urgente para a divulgação científica. São Paulo em Perspectiva, 14(3), 40-46, São Paulo.

Leite, B. S. (2015). Tecnologias no Ensino de Química: teoria e prática na formação docente. Appris.

Leite, L. S. P. et al. (2011). Tecnologia Educacional: descubra suas possibilidades na sala de aula. (6a ed.), Vozes.

Libâneo, J. C. (1983). Tendências pedagógicas na prática escolar. Revista da Ande. (6), 11-19.

Lima, V. R. et al. (2021). Metodologias ativas de ensino e aprendizagem: sala de aula invertida, instrução por colegas e júri simulado no ensino de Matemática. Research, Society and Development, 10(5). https://rsdjournal.org/index.php/rsd/article/view/14507/13096.

Macedo, L. N. et al. (2007) Desenvolvendo o pensamento proporcional com o uso de um objeto de aprendizagem. In: Brasil, Ministério da Educação. Secretaria de Educação a Distância. Objetos de aprendizagem: uma proposta de recurso pedagógico. Prata, C. L., \& Azevedo, A.C. (Org.). MEC/SEED, 2007. [online] htttp://rived.mec.gov.br/artigos/livro.pdf.

Machado, L. R. et al. (2011). Pedagogia, Andragogia e Gerontogogia utilizando objetos de aprendizagem ao longo da vida. Práticas em Informática na Educação. https://www.br-ie.org/pub/index.php/pie/article/viewFile/1311/1142.

Mastrela, R. (2016). Modelagem Matemática e as tecnologias da informação e comunicação no processo ensino aprendizagem. Dissertação. http://bit.profmat-sbm.org.br/xmlui/handle/123456789/1465

Mesquita, J. de M. et al. (2021) Softwares educativo aplicados no Ensino de Química: Recursos didáticos potencializadores no processo de aprendizagem. Research, Society and Development, 10(11). https://rsdjournal.org/index.php/rsd/article/view/15278/17725.

Miranda, G. L. (2007). Limite e possibilidades das TIC na educação. In: Sísifo/Revista de Ciências da Educação. http://ticsproeja.pbworks .com/f/limites+e+possibilidades.pdf

Moraes, R., \& Galiazzi, M. C. (2011). Análise Textual Discursiva. (2a ed.), Unijúi. Ijúi.

Moran, J. M. (2015). Mudando a educação com metodologias ativas. In: Souza. C. A. (Org.). Convergências Midiáticas, Educação e Cidadania: aproximações jovens. UEGP/PROEX. 
Research, Society and Development, v. 10, n. 12, e490101220787, 2021

(CC BY 4.0) | ISSN 2525-3409 | DOI: http://dx.doi.org/10.33448/rsd-v10i12.20787

Moreira, J. M. B. (2018). TIC: uma investigação na formação de professores e na transposição didática. 2018. Tese. www.pcm.uem.br/uploads/jussany-mariade-barros-moreira-17082018_1540403934.pdf.

Moreira. (2014). Portal dia-a-dia Educação: possibilidades e desafios para o ensino de Ciências. Dissertação (Mestrado em Educação para a Ciência e a Matemática). Universidade Estadual de Maringá, Maringá, Paraná, Brasil, http://www.educadores.diaadia.pr.gov.br/arquivos/File/fevereiro201 6/quimica_dissertac oes/di ssertacao_jussany_maria_barros_moreira.pdf.

Nascimento, A. C. A. (2007). Objetos de aprendizagem: a distância entre a promessa e a realidade. In: Brasil, Ministério da Educação. Secretaria de Educação a Distância. Objetos de aprendizagem: uma proposta de recurso pedagógico. Prata, C. L., \& Azevedo, A. C. (Org.). MEC/SEED, http://rived.mec.gov.br/artigos/livro.pdf.

Paraná. Secretaria de Estado da Educação. (2008). Diretrizes curriculares da educação básica: Biologia. SEED-PR. 74 p.

Prandini, R. C. (2009). Formação do formador para a atuação docente mediatizada pelas tecnologias da informação e comunicação. In: Hessel, A., Pesce, L., Alegretti, S. Formação online de educadores: identidade em construção. RG Editores. p. 63-88.

Reis, T. A.et al. (2010). O ensino de Genética e a atuação da mídia. http://connepi.ifal.edu.br/ocs/index.php/connepi/CONNEPI2010/paper/viewFile/851/574. 2010.

Rocha, S. C. (2016). O lúdico no ensino da Genética. In: Os desafios da escola pública paranaense na perspectiva do professor PDE: produções didáticopedagógicas. http://www.diaadiaeducacao.pr.gov.br/portals/cadernospde/pdebusca/producoes_pde/2016/2016_pdp_bio_ufpr_silvanacruzdarocha.pdf.

Silva, A. N. (2017). Os objetos de aprendizagem e suas potencialidades. XIV EVIDOSOL e XI CILTEC-Online - junho/2017. http://evidosol.textolivre.org/papers/2017/upload/9.pdf.

Souza, A., \& Souza, F. (2016) Uso da Plataforma Google Classroom como ferramenta de apoio ao processo de ensino e aprendizagem: relato de aplicação no ensino médio. https://repositorio.ufpb.br/jspui/bitstream/123456789/3315/1/ACSS30112016.pdf

Stinghen, R. S. (2016). Tecnologias na educação: dificuldade encontradas para utilizá-la no ambiente escolar. TCC. Universidade Federal de Santa Catarina. Florianópolis-SC. https://repositorio.ufsc.br/bitstream/handle/123456789/169794/TCC_Stinghen.pdf?sequence=1.

Tavares, R. (2008). Animações interativas e mapas conceituais: uma proposta para facilitar a aprendizagem significativa em Ciências. In: Ciências \& Cognição. 13 (2): 99-108. http://www.fisica.ufpb.br/ romero/pdf/2008AIMC.pdf

Temp, D. S., \& Bartholomei-Santos, M. L. (2018). O ensino de Genética: a visão de professores de Biologia. Rev. Cient. Schola. Colégio Militar de Santa Maria. Santa Maria, Rio Grande do Sul, Brasil. 83-95.

Valente, J. A. (2009). Análise dos diferentes tipos de softwares usados na Educação. http://www.nuted.ufrgs.br/edu3375_2009_2/links/s emana_3/analise_soft.pdf. 